\title{
KUALITAS PELAYANAN BERPENGARUH TERHADAP LOYALITAS PELANGGAN DENGAN KEPUASAN PELANGGAN SEBAGAI VARIABEL MEDIASI
}

\author{
I Gede Benny Subawa ${ }^{1}$ \\ Eka Sulistyawati \\ ${ }^{1,2}$ Fakultas Ekonomi dan Bisnis Universitas Udayana (Unud), Bali, Indonesia \\ email: ima@lila-travel.com
}

\begin{abstract}
ABSTRAK
Populasi dalam penelitian ini adalah pelanggan yang loyal menggunakan jasa Lila Tour and Travel selama kurun waktu 3 tahun terakhir untuk produk tour. Metode penentuan sampel yang digunakan adalah nonprobability sampling dengan teknik purposive sampling yaitu teknik penentuan sampel dengan pertimbangan tertentu. Sampel yang dipilih dalam penelitian ini sebanyak 100 responden. Data di analisis menggunakan teknik analisis jalur (path analysis). Hasil penelitian menunjukkan bahwa kualitas pelayanan berpengaruh positif dan signifikan terhadap kepuasan pelanggan, serta kualitas pelayanan dan kepuasan pelanggan berpengaruh positif dan signifikan terhadap loyalitas pelanggan pada perusahaan Lila Tour and Travel. Saran yang dapat diberikan mencapai kepuasan pelanggan dan loyalitas pelanggan yang optimal yaitu sebaiknya kualitas pelayanan yang diberikan perusahan ditingkatkan, dengan cara : melayani pelanggan dengan cepat, tanggap terhadap keluhan yang di sampaikan oleh pelanggan, memahami keinginan pelanggan, dan bersedia untuk memberikan informasi yang dibutuhkan pelanggan.
\end{abstract}

Kata Kunci: kualitas pelayanan, kepuasan pelanggan, loyalitas pelanggan

\begin{abstract}
The population in this study is loyal customers who use the services of Lila Tour and Travel for the past 3 years for tour products. The sampling method used is nonprobability sampling with a purposive sampling technique that is the sampling technique with certain considerations. The sample chosen in this study was 100 respondents. Data were analyzed using path analysis techniques. The results showed that service quality had a positive and significant effect on customer satisfaction, and service quality and customer satisfaction had a positive and significant effect on customer loyalty in the Lila Tour and Travel company. Suggestions that can be given to achieve customer satisfaction and optimal customer loyalty is that the quality of service provided by the company is improved, by: serving customers quickly, responding to complaints conveyed by customers, understanding customer desires, and willing to provide information needed by customers.

Keywords: service quality, customer satisfaction, customer loyalty
\end{abstract}




\section{PENDAHULUAN}

Pariwisata merupakan suatu kegiatan yang secara langsung menggunakan dan melibatkan masyarakat, sehingga memberikan berbagai keuntungan terhadap masyarakat setempat dan sekitarnya. Bahkan pariwisata dikatakan mempunyai energi yang sangat luar biasa, yang mampu membuat masyarakat setempat mengalami metamorfosis dalam berbagai aspeknya. Pada era terakhir ini, industri pariwisata telah menjadi salah satu komponen penting dari perekonomian dunia (Shahin \& Dabestani, 2010). Pengembangan di bidang pariwisata merupakan suatu hal yang sangat perlu dilakukan oleh pemerintah daerah, mengingat banyak sekali keuntungan atau manfaat yang bisa diambil dari kegiatan pariwisata, antara lain dapat menciptakan lapangan pekerjaan, memperkenalkan seni budaya daerah serta hasil kerajinan daerah tersebut.

Salah satu daerah pariwisata yang terkenal di Indonesia adalah Bali. Pulau Bali memperoleh peringkat pertama destinasi terbaik di Indonesia menurut Travellers' Choice Awards 2017. Keindahan alam, keunikan budaya dan keramahtamahan penduduk menjadikan Bali sebagai destinasi wisata dengan jumlah wisatawan yang sangat tinggi.

Tabel 1.

Jumlah Kunjungan Wisatawan Mancanegara yang Berkunjung ke Bali Periode 2012 - 2017

\begin{tabular}{ccc}
\hline Tahun & Jumlah Kunjungan & Pertumbuhan (\%) \\
\hline 2012 & 2.826 .709 & - \\
2013 & 2.949 .332 & 4,34 \\
2014 & 3.278 .598 & 11,16 \\
2015 & 3.766 .638 & 14,89 \\
2016 & 3.923 .949 & 4,18 \\
2017 & 4.927 .937 & 25,58 \\
& Rata-rata Pertumbuhan & $\mathbf{1 2 , 0 3}$ \\
\hline
\end{tabular}

Sumber: Badan Pusat Statistik Bali, 2017

Tabel 1. menunjukkan bahwa jumlah kunjungan wisatawan ke Bali mengalami kenaikan setiap tahunnya dengan rata-rata pertumbuhan $12,03 \%$. Berdasarkan informasi yang diperoleh dari Badan Pusat Statistik Provinsi Bali 2017, kedatangan wisatawan mancanegara (wisman) ke Bali pada bulan Agustus 2017 tercatat mencapai 601.884 kunjungan, dengan wisman yang datang melalui bandara sebanyak 599.827 kunjungan, dan yang melalui pelabuhan laut sebesar 2.057 kunjungan. Jumlah wisman ke Bali pada bulan Agustus 2017 naik sebesar 37,37 persen dibandingkan dengan catatan bulan Agustus 2016. Bila dibandingkan dengan bulan sebelumnya, jumlah wisman ke Bali juga tercatat mengalami peningkatan sebesar 1,66 persen. Menurut kebangsaan, wisman yang tercatat paling banyak datang ke Bali pada bulan Agustus 2017 adalah wisman dengan kebangsaan Tiongkok, Australia, Jepang, Perancis, dan Inggris dengan persentase masing-masing sebesar 26,05 persen, 16,67 persen, 6,11 persen, 4,93 persen, dan 4,71 persen. Meningkatnya jumlah wisatawan mancanegara ke Bali merupakan dampak positif dari meningkatnya kualitas sarana dan prasarana pariwisata di Bali. 
Pengembangan pariwisata tidak bisa terlepas dari sarana dan prasarana pendukungnya, sehingga Pemda dituntut untuk memberikan perhatian lebih apabila ingin pariwisata semakin maju dan berkembang. Oka (2005) mengatakan bahwa keberhasilan pengembangan pariwisata ditentukan oleh tiga faktor, yaitu 1) tersedianya obyek dan daya tarik wisata, 2) adanya fasilitas accessibility yaitu sarana dan prasarana yang memungkinkan wisatawan mengunjungi suatu daerah atau kawasan wisata dan 3) tersedianya fasilitas amenities yaitu sarana kepariwisataan yang dapat memberikan kenyamanan pelayanan kepada masyarakat.

Seiring dengan laju wisatawan yang berkunjung ke Bali dan sektor pariwisata yang semakin berkembang maka terciptalah travel agent atau Biro Perjalanan Wisata yang memiliki fungsi untuk memberikan kemudahan dalam mengakses informasi tentang pariwisata di Bali, pelayanan jasa perjalanan inbound dan outbound, serta pembuatan paket tour wisata di dalam dan diluar Bali. Travel agent atau Biro Perjalanan Wisata juga memberikan konstribusi yang besar dalam peningkatan jumlah wisatawan ini. Salah satu Travel agent yang turut serta dalam hal ini adalah Lila Tour and Travel.

Lila Tour and Travel adalah sebuah perusahaan travel agent yang mengkhususkan diri pada penyediaan jasa paket wisata dan tiket penerbangan. Lila Tour and Travel merupakan salah satu travel agent yang menawarkan berbagai pariwisata di Bali. Perusahaan ini biasa menerima permintaan via perorangan ataupun perusahaan. Lila Tour and Travel juga menyediakan pelayanan inbound dan outbound, pemesanan hotel hingga pemesanan restaurant di Bali. Pada umumnya proses permintaan dilakukan melalui telepon, e-mail atau dengan mengisi booking reservation form melalui website. Lila Tour and Travel ini didirikan sejak tahun 1997 oleh I Made Gede Subawa. Dalam menjalankan aktivitas bisnis di bidang biro perjalanan pariwisata selama lebih dari 10 tahun, Lila Tour and Travel telah memperoleh penghargaan yang sangat bergengsi baik di daerah maupun di tingkat nasional (www.lila-travel.com, 2017).

Pada tahun 2013 Lila Tour and Travel mendapat penghargaan sebagai "The Best Brand Award 2013" yang diselenggarakan oleh lembaga Bali Best Brand tingkat daerah. Selain itu, Lila Tour and Travel juga memperoleh penghargaan di tingkat nasional oleh Indonesia Quality Service Excellent sebagai pemenang pada kategori Tourism Award Winner 2011-2012 as "The Best Tour and Travel in Service Excellent of the year". Penghargaan bergengsi yang diperoleh sebagai agen travel terbaik dalam memberikan pelayanan terbaik ini, menunjukkan bahwa Lila Tour and Travel telah berupaya memberikan kualitas pelayanan yang memuaskan pada pelanggan, sehingga banyak wisatawan yang tertarik menggunakan jasa Lila Tour and Travel. Berikut terangkum jumlah wisatawan domestik maupun mancanegara yang menggunakan jasa Lila Tour and Travel selama periode 2014-2016.

Tabel 2. menunjukkan bahwa jumlah pelanggan Lila Tour and Travel mulai mengalami penurunan pada tahun 2014 hingga 2017. Rata-rata pertumbuhan pelanggan Lila Tour and Travel mengalami penurunan sebesar 0,29 persen. Kondisi tersebut tidak terlepas dari ketatnya persaingan di antara bisnis biro perjalanan pariwisata yang ada di Bali. Pelaku bisnis jasa ini bersaing untuk dapat menarik konsumen menggunakan jasa travel masing-masing. Dalam menarik konsumen, 
pemilik bisnis berusaha sebaik mungkin memberikan segala yang terbaik untuk memenuhi kepuasan konsumen (Ayu \& Edwar, 2011). Oleh karena itu, maka penting bagi Lila Tour and Travel untuk meningkatkan loyalitas pelanggan agar tidak beralih pada perusahaan travel lainnya.

Tabel 2.

Jumlah Pelanggan Lila Tour and Travel selama tahun 2014-2017

\begin{tabular}{ccc}
\hline Tahun & Jumlah Pelanggan & Pertumbuhan $(\%)$ \\
\hline 2014 & 3.949 & - \\
2015 & 4.027 & 1,97 \\
2016 & 3.971 & $-0,01$ \\
2017 & 3.858 & $-2,84$ \\
\multicolumn{2}{c}{ Rata-rata Pertumbuhan Pelanggan } & $\mathbf{- 0 . 2 9}$ \\
\hline
\end{tabular}

Sumber: Lila Tour and Travel, 2019

Menjaga para pelanggan agar tidak memilih produk pesaing tentu bukan perkara mudah. Perusahaan harus melakukan beberapa hal yang dapat mengikat hati pelanggan untuk tetap setia pada produk perusahaan. Salah satunya dengan pelayanan terbaik untuk pelanggan. Pelayanan terbaik tentu harus memahami kebutuhan dan keluhan para pelanggan. Sehingga pelayanan yang dilakukan oleh perusahaan tepat sasaran. Selain itu, kepuasan pelanggan ikut menjadi bagian penting untuk menjaga loyalitas pelanggan perusahaan (Henriawan, 2015). Alasan utama perusahaan jasa meningkatkan loyalitas pelanggan adalah membangun kesetiaan pada pelanggan dan mempertahankan pelanggan agar tidak pindah ke pesaingnya dan tetap menggunakan jasanya tanpa memerlukan biaya yang besar dengan cara meningkatkan kualitas pelayanan (jasa) dan lebih efisien mempertahankan konsumen setia daripada mencari konsumen baru (Pribadi, 2014).

Kualitas pelayanan merupakan faktor utama yang mempengaruhi loyalitas pelanggan dikarenakan pelanggan yang terpuaskan nilai pribadinya dan mengalami mood yang positif terhadap pelayanan akan memiliki loyalitas yang tinggi terhadap perusahaan tersebut. Pelanggan seringkali tidak loyal disebabkan oleh adanya pelayanan yang buruk atau kualitas pelayanan yang semakin menurun dari yang diharapkan pelanggan (Irnandha, 2016). Membangun kualitas pelayanan dan mengelola respon emosi pelanggan merupakan dasar bagi terbentuknya service loyalty. Dimana dibuktikan kualitas pelayanan mempengaruhi kepuasan pelanggan sehingga menjadi suatu respon kepada pelanggan atas apa yang sudah diterima. Kepuasan pelanggan menjadi pendorong terciptanya loyalitas pelanggan. Semakin tinggi kualitas pelayanan yang di berikan maka semakin tinggi pula loyalitas dan penciptaan respon emosi yang positif dari pelanggan (Haryono \& Evanita, 2015).

Kualitas pelayanan juga memiliki hubungan yang erat dengan kepuasan pelanggan, sehingga memberikan dorongan kepada pelanggan untuk menjalin ikatan yang kuat dengan perusahaan. Untuk mengetahui tingkat kepuasan pelanggan perlu terlebih dahulu mengetahui kualitas pelayanan yang diberikan produsen kepada pelangganya. Kepuasan pelanggan akan timbul setelah seseorang mengalami pengalaman dengan kualitas pengalaman yang diberikan oleh penyedia jasa (Irnandha, 2016). Penelitian yang dilakukan oleh Sumertana (2016), menunjukan bahwa terdapat pengaruh yang signifikan antara kualitas pelayanan 
dengan kepuasan pelanggan, kualitas pelayanan dapat berpengaruh langsung kepada loyalitas pelanggan dan dapat juga berpengaruh tidak langsung melalui kepuasan konsumen. Penelitian serupa oleh Karita et al. (2015) juga menyatakan bahwa kepuasan pelanggan mampu memediasi pengaruh kualitas produk terhadap loyalitas pelanggan. Peran mediasi yang dimiliki kepuasan pelanggan secara tidak langsung mempengaruhi kualitas produk terhadap loyalitas pelanggan.

Loyalitas dipengaruhi oleh kualitas layanan yang diberikan oleh perusahaan kepada konsumennya. Penelitian yang dilakukan oleh (Lee, 2013) menunjukkan hasil bahwa kualitas layanan perusahaan berpengaruh positif dan signifikan terhadap loyalitas pelanggan. Menurut Mosahab et al. (2010) dalam penelitiannya menunjukkan hasil bahwa kualitas layanan berpengaruh positif terhadap loyalitas pelanggan. Menurut penelitian yang telah dilakukan oleh Arab et al. (2012) kualitas layanan berpengaruh positif dan signifikan terhadap loyalitas pelanggan. Penelitian serupa yang dilakukan oleh Henriawan (2015), Haryono \& Evanita (2015), Prayoga et al. (2014), Aditya \& Kusumadewi (2017), Sinaga (2010), Irnandha (2016), Pribadi (2014), serta Apriyani \& Ekawati (2013) menemukan hasil bahwa kualitas pelayanan berpengaruh positif dan signifikan terhadap loyalitas pelanggan. Maka dari itu, dapat dinyatakan bahwa kualitas pelayanan berpengaruh terhadap loyalitas pelanggan. Berdasarkan uraian diatas maka hipotesis yang diajukan adalah

$\mathrm{H}_{1}$ : Kualitas pelayanan berpengaruh positif dan signifikan terhadap loyalitas pelanggan.

Penelitian yang telah dilakukan oleh Lee (2013) menunjukkan hasil bahwa kualitas layanan memiliki pengaruh yang positif terhadap kepuasan pelanggan. Menurut Siddiqi (2011) dalam penelitiannya menyatakan kepuasan pelanggan sangat dipengaruhi oleh kualitas layanan dari perusahaan. Penelitian serupa yang dilakukan oleh Merkusi \& Devilia (2015), Anggarayana \& Pramudana (2013), Ayu \& Edwar (2011), Prayoga et al. (2014), Aditya \& Kusumadewi (2017), serta Irnandha (2016) menemukan hasil bahwa kualitas pelayanan berpengaruh positif dan signifikan terhadap kepuasan pelanggan. Berdasarkan hasil penelitian sebelumnya diatas maka dapat dibangun hipotesis sebagai berikut.

$\mathrm{H}_{2}$ : Kualitas pelayanan berpengaruh positif dan signifikan terhadap kepuasan pelanggan.

Henriawan (2015) dalam penelitiannya menunjukkan hasilbahwa kepuasan pelanggan berpengaruh positif dan juga signifikan terhadaployalitas pelanggan. Pelanggan yang mendapatkan kepuasan secara otomatis akan menimbulkan sikap yang loyal terhadap produk yang memberinya kepuasan. Raharjo (2013) dalam penelitiannya menyatakan bahwa kepuasan berpengaruh positif terhadap loyalitas pelanggan. Penelitian yang sama juga dilakukan oleh Lee (2013) dengan hasil bahwa kepuasan pelanggan tidak hanya memiliki pengaruh positif terhadap loyalitas tetapi juga signifikan. Penelitian serupa yang dilakukan oleh Anggarayana \& Pramudana (2013), Prayoga et al. (2014), Aditya \& Kusumadewi (2017), Sinaga (2010), serta Irnandha (2016) juga menemukan hasil bahwa kepuasan pelanggan berpengaruh positif dan signifikan terhadap loyalitas pelanggan. Berdasarkan uraian diatas maka hipotesis yang akan diajukan adalah sebagai berikut :

$\mathrm{H}_{3}$ : Kepuasan pelanggan berpengaruh positif dan signifikan terhadap loyalitas pelanggan. 
Aryani \& Rosita (2010) dalam penelitiannya menunjukkan bahwa kepuasan dapat memediasi pengaruh kualitas layanan dengan loyalitas nasabah. Dimana nasabah yang merasa puas akan kualitas layanan yang diberikan olehperusahaan secara otomatis akan menimbulkan sikap yang loyal. Penelitian yang dilakukan oleh Andrianto \& Widyawati (2014) menunjukan bahwa kepuasan merupakan variabel yang dapat memediasi pengaruh kualitas layanan terhadap loyalitas konsumen. Penelitian yang sama juga dilakukan Singh \& Thakur (2012) dengan hasil bahwa kepuasan pelanggan memiliki peran yang sangat besar dalam memediasi hubungan kualitas layanan dengan loyalitas. Interaksi yang terjadi antara kualitas produk dengan kepuasan pelanggan semakin tinggi maka berdampak bahwa loyalitas pelanggan akan semakin tinggi. Maka, peran kepuasan sebagai variabel mediasi dapat memperkuat pengaruh kualitas produk terhadap loyalitas pelanggan (Karita et al., 2015). Penelitian serupa yang dilakukan oleh Aditya \& Kusumadewi (2017) juga memperoleh hasil bahwa kepuasan pelanggan mampu memediasi pengaruh kualitas pelayanan terhadap loyalitas pelanggan. Berdasarkan hasil penelitian sebelumnya diatas maka dapat dibangun hipotesis sebagai berikut.

$\mathrm{H}_{4}$ : Kepuasan pelanggan berpengaruh dalam memediasi kualitas pelanggan terhadap loyalitas pelanggan

\section{METODE PENELITIAN}

Lokasi yang dipilih sebagai lokasi penelitian adalah Kota Denpasar. Alasan dipilihnya Kota Denpasar sebagai lokasi adalah karena Denpasar merupakan kota strategis yang pilih oleh perusahaan Lila Tour and Travel untuk bersaing di Provinsi Bali. Banyaknya perusahaan jasa di bidang pariwisata di Kota Denpasar membuat perusahaan Lila Tour and Travel saling bersaing dengan kompetitornya dalam mengedepankan kualitas pelayanan demi menjaga pelanggan agar tetap loyal terhadap perusahaan.

Populasi dalam penelitian ini adalah pelanggan yang loyal menggunakan jasa Lila Tour and Travel selama kurun waktu 2 tahun terakhir. Metode penentuan sampel yang digunakan pada penelitian ini adalah nonprobability sampling dengan teknik purposive sampling yaitu teknik penentuan sampel dengan pertimbangan tertentu. Dalam penelitian ini teknik analisis yang digunakan adalah teknik analsis jalur (path analysis).

\section{HASIL DAN PEMBAHASAN}

Penelitian ini dilakukan untuk mengetahui pengaruh kualitas pelayanan terhadap kepuasan pelanggan dan untuk mengetahui pengaruh kualitas pelayanan serta kepuasan pelanggan terhadap loyalitas pelanggan. Penyebaran kuesioner dilakukan pada Lila Tour and Travel. Data karakteristik responden merupakan data responden yang dikumpulkan untuk mengetahui profil responden penelitian. Dari hasil penelitian yang dilakukan terhadap pelanggan Lila Tour and Travel, maka dapat diketahui gambaran karakteristik responden yang meliputi empat aspek, yaitu umur, jenis kelamin, pendidikan dan pekerjaan. 
Tabel 3.

Karakteristik Responden Berdasarkan Jenis Kelamin

\begin{tabular}{ccc}
\hline Jenis Kelamin & Jumlah (orang) & Persentase (\%) \\
\hline Laki-Laki & 42 & 42 \\
Perempuan & 58 & 58 \\
Jumlah & $\mathbf{1 0 0}$ & $\mathbf{1 0 0}$ \\
\hline
\end{tabular}

Sumber: Data diolah, 2019

Tabel 3. menunjukkan jumlah responden berjenis kelamin perempuan sebanyak 58 orang atau 58 persen, dan jumlah responden berjenis kelamin laki-laki sebanyak 42 orang atau 42 persen. Hal ini menunjukkan bahwa pelanggan Lila Tour and Travel di dominasi oleh responden berjenis kelamin perempuan. Pada umumnya memang lebih banyak kaum perempuan yang suka melakukan travelling baik seorang diri, bersama keluarga maupun bersama teman-temannya dibandingkan dengan kaum laki-laki. Apalagi jika mendapatkan informasi tiket transportasi yang sedang diskon dengan kualitas pelayanan yang baik, maka kaum perempuan cenderung lebih tertarik melakukan pembelian dibandingkan dengan laki-laki.

Tabel 4.

Karakteristik Responden Berdasarkan Umur

\begin{tabular}{ccc}
\hline Usia & Jumlah (orang) & Persentase $(\%)$ \\
\hline$\leq 20$ Tahun & 13 & 13 \\
$21-30$ Tahun & 53 & 53 \\
$31-40$ Tahun & 25 & 25 \\
$>$ 40 Tahun & 9 & 9 \\
Jumlah & $\mathbf{1 0 0}$ & $\mathbf{1 0 0}$ \\
\hline
\end{tabular}

Sumber: Data diolah, 2017

Tabel 4. menunjukkan bahwa responden yang pernah menggunakan jasa Lila Tour and Travel berasal dari berbagai macam usia. Kelompok responden yang paling banyak menggunakan jasa Lila Tour and Travel adalah responden dengan rentang usia 21-30 tahun. Pada usia 21-30 tahun merupakan usia dimana mereka menggunakan waktu liburnya untuk berlibur atau berpergian ke tempat-tempat yang jauh dari tempat tinggal mereka untuk sekedar mencari ketenangan, berlibur bersama keluarga atau melepas rindu ke kampung halaman mereka. Kelompok usia 21 - 30 tahun merupakan kelompok usia yang produktif yang baru lulus dari bangku kuliah dan sudah memperoleh pekerjaan, sehingga tidak memiliki beban keluarga dan mampu melakukan aktivitas travelling.

Tabel 5. menjelaskan bahwa jumlah responden yang pernah menggunakan jasa Lila Tour and Travel paling dominan adalah kelompok responden lulusan Sarjana. Pada umumnya kelompok sarjana, terutama yang baru mengalami kelulusan, banyak yang melakukan aktivitas travelling untuk merayakan kelulusan atau sekedar melepas beban setelah melalui perjuangan panjang dalam menyelesaikan pendidikannya. 
Tabel 5.

Karakteristik Responden Berdasarkan Pendidikan Terakhir

\begin{tabular}{lcc}
\hline \multicolumn{1}{c}{ Pendidikan terakhir } & Jumlah (orang) & Presentase (\%) \\
\hline SLTA/SMA & 7 & 7 \\
Diploma & 22 & 22 \\
Sarjana (S1) & 61 & 61 \\
Pasca Sarjana (S2) & 10 & 10 \\
\multicolumn{1}{c}{ Jumlah } & $\mathbf{1 0 0}$ & $\mathbf{1 0 0}$ \\
\hline
\end{tabular}

Sumber: Data diolah, 2019

Tabel 6.

Karakteristik Responden Berdasarkan Pekerjaan

\begin{tabular}{ccc}
\hline Pekerjaan & Jumlah (orang) & Persentase (\%) \\
\hline Mahasiswa & 9 & 9 \\
PNS & 18 & 18 \\
Swasta & 52 & 52 \\
Wiraswasta & 21 & 21 \\
Jumlah & $\mathbf{1 0 0}$ & $\mathbf{1 0 0}$ \\
\hline
\end{tabular}

Sumber: Data diolah, 2017

Tabel 6. menjelaskan bahwa jumlah responden yang pernah menggunakan jasa Lila Tour and Travel paling dominan adalah yang bekerja sebagai pegawai swasta. Responden dengan pekerjaan sebagai pegawai swasta memiliki pendapatan yang pasti setiap bulannya, sehingga dapat melakukan aktivitas travelling. Selain itu, tidak jarang pula pegawai swasta yang mendapat dinas kerja keluar kota, sehingga melakukan pembelian tiket pesawat melalui agen travel seperti jasa Lila Tour and Travel.

Uji asumsi klasik dilakukan dengan tujuan untuk memastikan hasil yang diperoleh memenuhi asumsi dasar di dalam analisis regresi. Hasil uji asumsi klasik yang dilakukan dalam penelitian ini adalah uji normalitas, uji multikoliniearitas dan uji heteroskedastisitas. Hasil dari uji asumsi klasik yang diolah dengan bantuan software SPSS 18.0 for Windows disajikan sebagai berikut.

Uji normalitas bertujuan untuk mengetahui apakah residual dari model regresi yang dibuat berdistribusi normal atau tidak. Untuk menguji apakah data yang digunakan normal atau tidak dapat dilakukan dengan menggunakan uji Kolmogorov Sminarnov. Apabila koefisien Asymp. Sig. (2-tailed) lebih besar dari 0,05 maka data tersebut dikatakan berdistribusi normal.

Berdasarkan Tabel 7. dapat dilihat bahwa nilai Kolmogorov Sminarnov (K-S) sebesar 0,808, sedangkan nilai Asymp. Sig. (2-tailed) sebesar 0,531. Hasil tersebut mengindikasikan bahwa model persamaan regresi tersebut berdistribusi normal karena nilai Asymp. Sig. (2-tailed) lebih besar dari nilai alpha 0,05.

Berdasarkan Tabel 8. dapat dilihat bahwa nilai Kolmogorov Sminarnov (KS) sebesar 0,795, sedangkan nilai Asymp. Sig. (2-tailed) sebesar 0,552. Hasil tersebut mengindikasikan bahwa model persamaan regresi tersebut berdistribusi normal karena nilai Asymp. Sig. (2-tailed) lebih besar dari nilai alpha 0,05. 
Tabel 7.

Hasil Uji Normalitas Struktur 1

\begin{tabular}{lc}
\hline & Unstandardized Residual \\
\hline $\mathrm{N}$ & 100 \\
Kolmogorov-Smirnov $Z$ & 0,808 \\
Asymp.Sig.(2-tailed) & 0,531 \\
\hline Sumber: Data diolah, 2017 &
\end{tabular}

Tabel 8.

Hasil Uji Normalitas Struktur 2

\begin{tabular}{lc}
\hline & Unstandardized Residual \\
\hline $\mathrm{N}$ & 100 \\
Kolmogorov-Smirnov Z & 0,795 \\
Asymp.Sig.(2-tailed) & 0,552 \\
\hline Sumber: Data dil
\end{tabular}

Sumber: Data diolah, 2017

Uji multikolinieritas bertujuan untuk menguji apakah pada model regresi ditemukan adanya korelasi antar variabel bebas. Adanya multikolinearitas dapat dilihat dari nilai tolerance atau variance inflation factor (VIF). Jika nilai tolerance lebih dari $10 \%$ atau VIF Kurang dari 10, maka dikatakan tidak ada multikolinearitas.

Tabel 9.

Hasil Uji Multikoleniaritas

\begin{tabular}{lcc}
\hline \multicolumn{1}{c}{ Variabel } & Tolerance & VIF \\
\hline Kualitas Pelayanan $(\mathrm{X})$ & 0,574 & 1,743 \\
Kepuasan Pelanggan $\left(\mathrm{Y}_{1}\right)$ & 0,574 & 1,743 \\
\hline Sumber: Data diolah, 2017 & &
\end{tabular}

Berdasarkan Tabel 9. dapat dilihat bahwa nilai tolerance dan VIF dari variabel kualitas pelayanan, dan kepuasan pelanggan menunjukkan nilai tolerance untuk setiap variabel lebih besar dari $10 \%$ dan nilai VIF lebih kecil dari 10 yang berarti model persamaan regresi bebas dari multikolinearitas.

Uji heterokedastisitas bertujuan untuk mengetahui apakah dalam model regresi terjadi ketidaksamaan varians dari residual satu pengamatan ke pengamatan yang lain dan pengujian ini dilakukan dengan uji Glejser. Jika nilai signifikansinya di atas 0,05 maka tidak mengandung gejala heteroskedastisitas.

Tabel 10.

Hasil Uji Heteroskedastisitas Struktur 1

\begin{tabular}{|c|c|c|c|c|c|c|}
\hline \multirow{2}{*}{\multicolumn{2}{|c|}{ Model }} & \multicolumn{2}{|c|}{$\begin{array}{l}\text { Unstandardized } \\
\text { Coefficients }\end{array}$} & \multirow{2}{*}{$\begin{array}{c}\text { Standardized } \\
\text { Coefficients } \\
\text { Beta }\end{array}$} & \multirow[b]{2}{*}{$\mathbf{t}$} & \multirow[b]{2}{*}{ Sig. } \\
\hline & & B & Std. Error & & & \\
\hline \multirow[t]{2}{*}{1} & (Constant) & 1.018 & .947 & & 1.075 & .285 \\
\hline & Kualitas Pelayanan & .007 & .023 & .032 & .317 & .752 \\
\hline
\end{tabular}

Sumber: Data diolah, 2019

Pada Tabel 10. dapat dilihat bahwa nilai signifikansi dari variabel kualitas pelayanan sebesar 0,752 . Nilai tersebut lebih besar dari 0,05 yang berarti tidak 
terdapat pengaruh antara variabel bebas terhadap absolute residual. Dengan demikian, model yang dibuat tidak mengandung gejala heteroskedastisitas.

Tabel 11.

Hasil Uji Heteroskedastisitas Struktur 2

\begin{tabular}{|c|c|c|c|c|c|c|}
\hline \multirow{2}{*}{\multicolumn{2}{|c|}{ Model }} & \multicolumn{2}{|c|}{$\begin{array}{l}\text { Unstandardized } \\
\text { Coefficients }\end{array}$} & \multirow{2}{*}{$\begin{array}{c}\text { Standardized } \\
\text { Coefficients } \\
\text { Beta }\end{array}$} & \multirow[b]{2}{*}{$\mathbf{t}$} & \multirow[b]{2}{*}{ Sig. } \\
\hline & & B & Std. Error & & & \\
\hline \multirow[t]{3}{*}{1} & (Constant) & 2.681 & 1.073 & & 2.498 & .014 \\
\hline & Kualitas Pelayanan & .006 & .034 & .024 & .181 & .857 \\
\hline & Kepuasan Pelanggan & -.089 & .071 & -.166 & -1.252 & .214 \\
\hline
\end{tabular}

Pada Tabel 11. dapat dilihat bahwa nilai signifikansi dari variabel kualitas pelayanan, dan kepuasan pelanggan, masing-masing sebesar 0,857 dan 0,214. Nilai tersebut lebih besar dari 0,05 yang berarti tidak terdapat pengaruh antara variabel bebas terhadap absolute residual. Dengan demikian, model yang dibuat tidak mengandung gejala heteroskedastisitas.

Perhitungan koefisien path dilakukan dengan analisis regresi melalui software SPSS 18.0 for Windows, diperoleh hasil yang ditunjukan pada Tabel 12. berikut:

Tabel 12.

Hasil Analisis Jalur 1

\begin{tabular}{lcccc}
\hline \multicolumn{1}{c}{ Variabel } & Unstandardized Beta & Std. Error & t hitung & Sig. uji t \\
\hline (Constant) & 3,130 & 1,486 & 2,105 & 0,038 \\
Kualitas Pelayanan (X) & 0,314 & 0,037 & 8,535 & 0,000 \\
R Square & 0,426 & & & \\
F Statistik & 72,839 & & \\
Signifikansi Uji F & 0,000 & & & \\
\hline
\end{tabular}

Sumber: Data diolah, 2019

Berdasarkan hasil analisis jalur substruktur 1 seperti yang disajikan pada Tabel 12, maka dapat dibuat persamaan struktural sebagai berikut:

$$
\mathrm{Y}_{1}=0,314 \mathrm{X}+\mathrm{e}_{1}
$$

Nilai koefisien regresi variabel kualitas pelayanan bernilai positif dengan nilai signifikansi uji t kurang dari 0,05 . Hal ini menunjukkan bahwa variabel kualitas pelayanan memiliki pengaruh positif yang signifikan terhadap variabel kepuasan pelanggan. Besarnya pengaruh variabel bebas terhadap variabel terikat yang ditunjukkan oleh nilai determinasi total (R Square) sebesar 0,426 mempunyai arti bahwa sebesar $42,6 \%$ variasi kepuasan pelanggan dipengaruhi oleh variasi kualitas pelayanan, sedangkan sisanya sebesar 57,4\% dijelaskan oleh faktor lain yang tidak dimasukkan ke dalam model. 
Tabel 13.

Hasil Analisis Jalur 2

\begin{tabular}{lcccc}
\hline \multicolumn{1}{c}{ Variabel } & Unstandardized Beta & Std. Error & $\begin{array}{c}\text { t } \\
\text { hitung }\end{array}$ & Sig. uji t \\
\hline (Constant) & 4,232 & 1,744 & 2,426 & 0,017 \\
Kualitas Pelayanan (X) & 0,131 & 0,056 & 2,352 & 0,021 \\
Kepuasan Pelanggan (Y) & 0,409 & 0,116 & 3,528 & 0,001 \\
R Square & 0,341 & & & \\
F Statistik & 25,118 & & & \\
Signifikansi Uji F & 0,000 & & & \\
Sumber: Data diolah, 2017 & & &
\end{tabular}

Berdasarkan hasil analisis jalur substruktur 2 seperti yang disajikan pada Tabel 13, maka dapat dibuat persamaan struktural sebagai berikut :

$$
\begin{aligned}
& \mathrm{Y}_{2}=\beta_{2} \mathrm{X}+\beta_{3} \mathrm{Y}_{1}+\mathrm{e}_{2} \ldots \ldots \ldots \ldots \ldots \ldots \\
& \mathrm{Y}_{2}=0,131 \mathrm{X}+0,409 \mathrm{Y}_{1}+\mathrm{e}_{2}
\end{aligned}
$$

Nilai koefisien regresi masing-masing variabel bebas bernilai positif dengan nilai signifikansi uji t kurang dari 0,05 . Hal ini menunjukkan bahwa semua variabel bebas memiliki pengaruh positif yang signifikan terhadap variabel terikat. Besarnya pengaruh variabel bebas terhadap variabel terikat yang ditunjukkan oleh nilai determinasi total (R Square) sebesar 0,341 mempunyai arti bahwa sebesar 34,1\% variasi loyalitas pelanggan dipengaruhi oleh variasi kualitas pelayanan dan kepuasan pelanggan, sedangkan sisanya sebesar $65,9 \%$ dijelaskan oleh faktor lain yang tidak dimasukkan ke dalam model.

Berdasarkan model substruktur 1 dan substruktur 2, maka dapat disusun model diagram jalur akhir. Sebelum menyusun model diagram jalur akhir, terlebih dahulu dihitung nilai standar eror sebagai berikut :

$$
\begin{aligned}
& P e_{i}=\sqrt{1-R_{i}^{2}} \\
& \mathrm{Pe}_{1}=\sqrt{1-R_{1}{ }^{2}}=\sqrt{1-0,426}=0,757 \\
& \mathrm{Pe}_{2}=\sqrt{1-{K_{2}}^{2}}=\sqrt{1-0,341}=0,812
\end{aligned}
$$

Berdasarkan perhitungan pengaruh error (Pei), didapatkan hasil pengaruh error $\left(\mathrm{Pe}_{1}\right)$ sebesar 0,757 dan pengaruh error $\left(\mathrm{Pe}_{2}\right)$ sebesar 0,812 . Hasil koefisien determinasi total adalah sebagai berikut :

$$
\begin{aligned}
\mathrm{R}_{\mathrm{m}}{ }_{\mathrm{m}} & =1-\left(\mathrm{Pe}_{1}\right)^{2}\left(\mathrm{Pe}_{2}\right)^{2} \\
& =1-(0,757)^{2}(0,812)^{2} \\
& =1-(0,573)(0,659) \\
& =1-0,377=0,623
\end{aligned}
$$

Nilai determinasi total sebesar 0,623 mempunyai arti bahwa sebesar 62,3\% variasi loyalitas pelanggan dipengaruhi oleh variasi kualitas pelayanan dan kepuasan pelanggan, sedangkan sisanya sebesar 37,7\% djelaskan oleh faktor lain yang tidak dimasukkan ke dalam model.

Kriteria pengujian untuk menjelaskan interpretasi pengaruh antar masingmasing variabel yakni apabila nilai signifikansi $<0,05$ maka $\mathrm{H}_{0}$ ditolak dan $\mathrm{H}_{1}$ diterima. Sebaliknya, jika nilai signifikansi > 0,05 maka $\mathrm{H}_{0}$ diterima dan $\mathrm{H}_{1}$ ditolak. 
Berdasarkan hasil analisis pengaruh Kualitas Pelayanan terhadap Kepuasan Pelanggan diperoleh nilai Signifikansi sebesar 0,000 dengan nilai koefisien beta 0,314. Nilai Signifikansi $0,000<0,05$ mengindikasikan bahwa $\mathrm{H}_{0}$ ditolak dan $\mathrm{H}_{1}$ diterima. Hasil ini mempunyai arti bahwa Kualitas Pelayanan berpengaruh positif dan signifikan terhadap Kepuasan Pelanggan Lila Tour and Travel. Artinya, semakin baik kualitas pelayanan yang diberikan, maka kepuasan pelanggan Lila Tour and Travel akan semakin meningkat.

Berdasarkan hasil analisis pengaruh Kualitas Pelayanan terhadap Loyalitas Pelanggan diperoleh nilai Signifikansi sebesar 0,021 dengan nilai koefisien beta 0,131. Nilai Signifikansi 0,021 <0,05 mengindikasikan bahwa $\mathrm{H}_{0}$ ditolak dan $\mathrm{H}_{2}$ diterima. Hasil ini mempunyai arti bahwa Kualitas Pelayanan berpengaruh positif dan signifikan terhadap Loyalitas Pelanggan Lila Tour and Travel. Artinya, semakin baik kualitas pelayanan yang diberikan, maka kepuasan pelanggan Lila Tour and Travel akan semakin meningkat.

Berdasarkan hasil analisis pengaruh Kepuasan Pelanggan terhadap Loyalitas Pelanggan diperoleh nilai Signifikansi sebesar 0,001 dengan nilai koefisien beta 0,409. Nilai Signifikansi 0,001 < 0,05 mengindikasikan bahwa $\mathrm{H}_{0}$ ditolak dan $\mathrm{H}_{3}$ diterima. Hasil ini mempunyai arti bahwa Kepuasan Pelanggan berpengaruh positif dan signifikan terhadap Loyalitas Pelanggan Lila Tour and Travel. Artinya, apabila seseorang pelanggan berada pada tingkat kepuasan yang dinginkan, maka perilaku pelanggan untuk loyal pada perusahaan juga akan meningkat.

Perhitungan pengaruh antar variabel dirangkum dalam Tabel 14. sebagai berikut.

Tabel 14.

Pengaruh Langsung dan Pengaruh Tidak Langsung serta Pengaruh Total Kualitas Pelayanan (X1), Kepuasan Pelanggan (Y1), dan Loyalitas Pelanggan (Y)

\begin{tabular}{cccc}
\hline $\begin{array}{c}\text { Pengaruh } \\
\text { Variabel }\end{array}$ & $\begin{array}{c}\text { Pengaruh } \\
\text { Langsung }\end{array}$ & $\begin{array}{c}\text { Pengaruh Tidak Langsung Melalui } \\
\text { Kepuasan Pelanggan } \\
(\text { Y1 })(\boldsymbol{\beta} 1 \mathbf{x} \boldsymbol{\beta} \text { 3 })\end{array}$ & Pengaruh Total \\
\hline $\mathrm{X} \rightarrow \mathrm{M}$ & 0,314 & - & 0,314 \\
$\mathrm{X} \rightarrow \mathrm{Y}$ & 0,131 & 0,128 & 0,259 \\
$\mathrm{M} \rightarrow \mathrm{Y}$ & 0,409 & - & 0,409 \\
\hline
\end{tabular}

Sumber: Data diolah, 2017

Uji sobel merupakan alat analisis untuk menguji signifikansi dari hubungan tidak langsung antara variabel independen dengan variabel dependen yang dimediasi oleh variabel mediator. Uji Sobel dirumuskan dengan persamaan berikut dan dapat dihitung dengan menggunakan aplikasi Microsoft Excel 2007. Bila nilai kalkulasi Z lebih besar dari 1,96 (dengan tingkat kepercayaan 95 persen), maka variabel mediator dinilai secara signifikan memediasi hubungan antara variabel terikat dan variabel bebas.

$$
\begin{aligned}
& \left.Z=\frac{a}{\sqrt{b^{2} s_{a}^{2}+u^{2} s_{D}^{2}+s_{a}^{2} s_{D}^{2}}} \ldots \ldots \ldots \ldots \ldots \ldots \ldots . . . . . .4\right) \\
& \mathrm{Sig}=(1-\operatorname{NORMDIST}(\mathrm{Z}))+2)) \ldots \ldots \ldots \ldots \ldots \ldots .(5)
\end{aligned}
$$


Keterangan :

$$
\begin{aligned}
& a=0,314 \\
& S_{a}=0,037 \\
& b=0,409 \\
& S_{b}=0,116
\end{aligned}
$$

$$
\begin{gathered}
Z=\frac{0,314 \cdot 0,409}{\sqrt{(0,409)^{2}(0,037)^{2}+(0,314)^{2}(0,116)^{2}+(0,037)^{2}(0,116)^{2}}} \\
Z=\frac{0,128426}{\sqrt{0,000229+0,0013267+0,0000184}} \\
Z=\frac{0,128426}{\sqrt{0,039675}} \\
\mathbf{Z}=\mathbf{3 , 2 3 6 9}
\end{gathered}
$$

Tabel 15. Hasil Uji Sobel

\begin{tabular}{rc}
\hline Nilai $\mathbf{Z}$ & Sig \\
\hline 3,2369 & 0,001 \\
\hline Sumber: Data diolah, 2017 &
\end{tabular}

Sumber: Data diolah, 2017

Berdasarkan hasil Uji Sobel pada Tabel 15. menunjukkan bahwa hasil tabulasi $\mathrm{Z}=3,2369>1,96$ dengan tingkat signifikansi $0,001<0,05$ yang berarti variabel mediator yakni kepuasan pelanggan dinilai secara signifikansi memediasi hubungan antara kualitas pelayanan terhadap loyalitas pelanggan.

Hasil analisis menunjukkan bahwa kualitas pelayanan berpengaruh positif dan signifikan terhadap kepuasan pelanggan. Hal ini memiliki makna bahwa semakin baik kualitas pelayanan yang diberikan Lila Tour and Travel, maka akan semakin tinggi pula kepuasan yang dirasakan pelanggan. Begitu pula sebaliknya, semakin buruk kualitas pelayanan yang diberikan Lila Tour and Travel maka semakin rendah tingkat kepuasan pelanggan pada Lila Tour and Travel.

Hasil tersebut mengindikasikan bahwa nilai - nilai yang terkandung dalam kualitas pelayanan mampu dipersepsikan dengan baik dan berdampak nyata terhadap kepuasan pelanggan Lila Tour and Travel. Penampilan pegawai di kantor Lila Tour and Travel yang menarik, proses reservasi yang diberikan mudah dilakukan, karyawan bersedia untuk memberikan informasi yang dibutuhkan pelanggan, mampu menjelaskan informasi dengan baik dan jelas, dan mampu berkomunikasi dengan baik terhadap pelanggan, memiliki pengaruh untuk meningkatkan kepuasan pelanggan, sehingga pelanggan akan membicarakan halhal positif tentang perusahaan Lila Tour and Travel.

Kualitas pelayanan yang diukur berdasarkan indikator: bukti fisik, kehandalan, daya tanggap, jaminan dan empati, terbukti mampu meningkatkan kepuasan pelanggan Lila Tour and Travel. Temuan ini dapat diartikan bahwa apabila intensitas kualitas pelayanan pada Lila Tour and Travel ditingkatkan, maka 
akan mampu memberikan kontribusi yang signifikan untuk meningkatkan kepuasan pelanggan.

Penelitian ini mendukung beberapa hasil penelitian sebelumnya dan konsisten dengan hasil penelitian Chanming \& Jianjun (2011), Lee (2013), Siddiqi (2011), Merkusi \& Devilia (2015), Anggarayana \& Pramudana (2013), Ayu \& Edwar (2011), Prayoga et al. (2014), Aditya \& Kusumadewi (2017), serta Irnandha (2016) yang menunjukkan bahwa, terdapat hubungan yang positif dan signifikan antara kualitas pelayanan terhadap kepuasan pelanggan.

Hasil analisis menunjukkan bahwa kualitas pelayanan berpengaruh positif dan signifikan terhadap loyalitas pelanggan. Hal ini memiliki makna bahwa semakin baik kualitas pelayanan yang diberikan Lila Tour and Travel, maka akan semakin tinggi pula loyalitas pelanggan. Begitu pula sebaliknya, semakin buruk kualitas pelayanan yang diberikan Lila Tour and Travel maka semakin rendah loyalitas pelanggan pada Lila Tour and Travel.

Hasil tersebut mengindikasikan bahwa nilai - nilai yang terkandung dalam kualitas pelayanan mampu dipersepsikan dengan baik dan berdampak nyata terhadap loyalitas pelanggan Lila Tour and Travel. Penampilan pegawai di kantor Lila Tour and Travel yang menarik, proses reservasi yang diberikan mudah dilakukan, karyawan bersedia untuk memberikan informasi yang dibutuhkan pelanggan, mampu menjelaskan informasi dengan baik dan jelas, dan mampu berkomunikasi dengan baik terhadap pelanggan, memiliki pengaruh untuk meningkatkan loyalitas pelanggan, sehingga pelanggan akan menggunakan kembali jasa Lila Tour and Travel di masa yang akan datang

Kualitas pelayanan yang diukur berdasarkan indikator: bukti fisik, kehandalan, daya tanggap, jaminan dan empati, terbukti mampu meningkatkan kepuasan pelanggan Lila Tour and Travel. Temuan ini dapat diartikan bahwa apabila intensitas kualitas pelayanan pada Lila Tour and Travel ditingkatkan, maka akan mampu memberikan kontribusi yang signifikan untuk meningkatkan loyalitas pelanggan.

Penelitian ini mendukung beberapa hasil penelitian sebelumnya dan konsisten dengan hasil penelitian Lee (2013), Mosahab et al. (2010), Arab et al. (2012), Henriawan (2015), Haryono \& Evanita (2015), Prayoga et al. (2014), Aditya \& Kusumadewi (2017), Sinaga (2010), Irnandha (2016), Pribadi (2014), serta Apriyani \& Ekawati (2013) yang menunjukkan bahwa, terdapat hubungan yang positif dan signifikan antara kualitas pelayanan terhadap loyalitas pelanggan.

Hasil analisis menunjukkan bahwa kepuasan pelangan berpengaruh positif dan signifikan terhadap loyalitas pelanggan. Hal ini memiliki makna bahwa semakin puas pelanggan terhadap layanan yang diberikan Lila Tour and Travel, maka akan semakin tinggi pula loyalitas pelanggan. Begitu pula sebaliknya, semakin tidak puas pelanggan terhadap pelayanan yang diberikan Lila Tour and Travel maka semakin rendah loyalitas pelanggan pada Lila Tour and Travel.

Hasil tersebut mengindikasikan bahwa nilai - nilai yang terkandung dalam kepuasan pelanggan mampu dipersepsikan dengan baik dan berdampak nyata terhadap loyalitas pelanggan Lila Tour and Travel. Pelanggan yang merasa puas dalam menggunakan jasa Lila Tour and Travel dan membicarakan hal-hal positif 
tentang perusahaan Lila Tour and Travel, menunjukkan bahwa mereka loyal dan akan menggunakan kembali jasa Lila Tour and Travel di masa yang akan datang

Kepuasan pelanggan yang diukur berdasarkan indikator: mampu memenuhi harapan pelanggan, merasa puas dalam menggunakan jasa, merasa puas terhadap fasilitas yang diberikan dan tarif yang diberikan sesuai ekspektasi pelanggan, terbukti mampu meningkatkan loyalitas pelanggan Lila Tour and Travel. Temuan ini dapat diartikan bahwa apabila kepuasan pelanggan pada layanan jasa Lila Tour and Travel ditingkatkan, maka akan mampu memberikan kontribusi yang signifikan untuk meningkatkan loyalitas pelanggan.

Penelitian ini mendukung beberapa hasil penelitian sebelumnya dan konsisten dengan hasil penelitian Caceres \& Paparoidamis (2005), Raharjo (2013), Lee (2013), Henriawan (2015), Anggarayana \& Pramudana (2013), Prayoga et al. (2014), Aditya \& Kusumadewi (2017), Sinaga (2010), serta Irnandha (2016) yang menunjukkan bahwa, terdapat hubungan yang positif dan signifikan antara kepuasan pelanggan terhadap loyalitas pelanggan.

Pengaruh kualitas pelayanan terhadap loyalitas pelanggan akan lebih meningkat jika melalui kepuasan pelanggan. Loyalitas pelanggan Lila Tour And Travel dipengaruhi oleh faktor-faktor kualitas pelayanan yang terdiri dari bukti fisik, kehandalan, daya tanggap, jaminan, dan empati melalui kepuasan pelanggan. Persepsi pelanggan terhadap kualitas pelayanan akan berpengaruh terhadap Loyalitas pelanggan jika kepuasan pelanggan terpenuhi. Berdasarkan hasil pengujian pada hipotesis, ditemukan hasil bahwa nilai $\mathrm{Z}=3,237>1,96$ dengan tingkat signifikansi $0,001<0,05$ yang berarti variabel mediator yakni kepuasan pelanggan dinilai secara signifikansi memediasi hubungan antara kualitas pelayanan terhadap loyalitas pelanggan, yang artinya $\mathrm{H}_{4}$ diterima. Hasil penelitian ini didukung oleh penelitian Aryani \& Rosita (2010), Andrianto \& Widyawati (2014), Singh \& Thakur (2012), Karita et al. (2015), serta Aditya \& Kusumadewi (2017) yang menemukan hasil bahwa kepuasan pelanggan mampu memediasi pengaruh kualitas pelayanan terhadap loyalitas pelanggan. Artinya, kualitas pelayanan berpengaruh secara positif dan signifikan terhadap loyalitas pelanggan melalui kepuasan pelanggan.

Lila Tour \& Travel sebaiknya lebih memberikan perhatian khusus di bidang pengembangan teknologi mengingat peran teknologi yang saat ini sangat di gemari dan dapat mempermudah konsumen dan calon konsumen dalam mengakses informasi produk dan layanan yang di miliki oleh Lila Travel \& Tour. Dan apabila perusahaan mampu bersaing dan tetap secara stabil muncul pada media media komunikasi dan informasi yang di akses oleh masyakarat, hal ini dapat menambah nilai tambah yang perusahaan miliki dan tentunya akan berdampak kepada kenyamanan konsumen dalam pencarian informasi terkait produk dan layanan yang Lila Travel \& Tour miliki.

Hasil analisis menunjukkan bahwa kualitas pelayanan dan kepuasan pelanggan berpengaruh positif dan signifikan terhadap loyalitas pelanggan, maka pihak manajemen Lila Tour And Travel dapat mempertimbangkan faktor kualitas pelayanan dan kepuasan pelanggan tersebut untuk lebih ditingkatkan dan di evaluasi kembali agar dapat membentuk loyalitas pelanggan yang semakin meningkat. 
Hasil dari penelitian ini diharapkan mampu mendorong peneliti-peneliti selanjutnya untuk mengamati faktor-faktor lain yang dapat mempengaruhi loyalitas pelanggan selain kualitas pelayanan dan kepuasan pelanggan. Penelitian selanjutnya juga diharapkan dapat menambah jumlah sampel penelitian serta memperluas wilayah sampel peneliti, sehingga nanti hasilnya dapat digeneralisasikan untuk lingkup yang lebih luas.

Penelitian yang dilakukan diharapkan dapat memberikan kontribusi mengenai pengaruh kualitas pelayanan terhadap loyalitas pelanggan dengan kepuasan pelanggan sebagai variabel mediasi. Hasil uji hipotesis dalam penelitian ini ditemukan bahwa kepuasan pelanggan secara statistik mampu memediasi pengaruh kualitas pelayanan terhadap loyalitas pelanggan, sehingga variabel tersebut dapat dipertahankan sebagai variabel mediasi.

Ruang lingkup penelitian terbatas pada wilayah Kota Denpasar, sehingga hasil penelitian ini tidak dapat di generalisir untuk konsumen Lila Tour And Travel di luar Kota Denpasar. Bagi peneliti berikutnya sebaiknya memperluas ruang lingkup penelitian, sehingga tidak terbatas pada Kota Denpasar saja dan hasil penelitian dapat di generalisir.

Faktor yang mempengaruhi loyalitas pelanggan dalam penelitian ini adalah kualitas pelayanan dan kepuasan pelanggan, sedangkan masih banyak faktor lain yang mempengaruhi loyalitas pelanggan seperti kepercayaan, kemudahan, dan faktor-faktor lainnya. Penelitian ini hanya dilakukan dalam titik waktu tertentu (cross section), sedangkan lingkungan setiap saat berubah (dinamis), sehingga penelitian ini penting untuk dilakukan kembali.

\section{SIMPULAN}

Kualitas pelayanan berpengaruh positif dan signifikan terhadap Loyalitas Pelanggan pada perusahaan Lila Tour and Travel. Artinya, semakin baik kualitas pelayanan yang diberikan perusahaan Lila Tour and Travel, maka akan semakin meningkatkan loyalitas pelanggan. Kualitas pelayanan berpengaruh positif dan signifikan terhadap kepuasan pelanggan pada perusahaan Lila Tour and Travel. Artinya, semakin baik kualitas pelayanan yang diberikan perusahaan Lila Tour and Travel, maka akan semakin meningkatkan rasa kepuasan pelanggan.

Kepuasan Pelanggan berpengaruh positif dan signifikan terhadap Loyalitas Pelanggan pada perusahaan Lila Tour and Travel. Artinya, semakin puas pelanggan terhadap pelayanan yang diberikan, maka loyalitas pelanggan akan semakin meningkat pada perusahaan Lila Tour and Travel. Kepuasan pelanggan mampu memediasi pengaruh kualitas pelayanan terhadap loyalitas pelanggan pada perusahaan Lila Tour and Travel. Artinya, pengaruh kualitas pelayanan terhadap loyalitas pelanggan akan lebih meningkat jika melalui kepuasan pelanggan.

Kualitas pelayanan hendaknya di tingkatkan dengan cara : melayani pelanggan dengan cepat, tanggap terhadap keluhan yang di sampaikan oleh pelanggan, memahami keinginan pelanggan, dan bersedia untuk memberikan informasi yang dibutuhkan pelanggan.

Lila Tour and Travel hendaknya mampu memenuhi harapan pelanggan, dan memberikan fasilitas yang dapat memudahka pelanggan dalam dalam 
menggunakan jasa Lila Tour and Travel. Perusahaan sebaiknya menciptakan inovasi dan mengemas produk jasa yang ditawarkan agar lebih menarik, sehingga pelanggan tidak tertarik untuk menggunakan produk jasa selain Lila Tour and Travel.

\section{REFERENSI}

Aditya, P. M., \& Kusumadewi, N. M. W. (2017). Peran Kepuasan Pelanggan Dalam Memediasi Pengaruh Kualitas Pelayanan Terhadap Loyalitas Pelanggan. EJurnal Manajemen Unud, 6(9), 5061-5087.

Andrianto, R. R., \& Widyawati, N. (2014). Pengaruh Kualitas Pelayanan terhadap Loyalitas Dimediasi Kepuasan Konsumen Pada PT. JNE Surabaya. Jurnal Ilmu Dan Riset Akuntansi, 3(9), 1-21.

Anggarayana, W. D. P. G., \& Pramudana, K. A. S. (2013). Pengaruh Kualitas Layanan Terhadap Kepuasan Pelanggan dan Loyalitas Pelanggan Pada UD. Dewa Putu Toris Gianyar. E-Jurnal Manajemen Universitas Udayana, 2(10), 1346-1360.

Apriyani, A. S. K., \& Ekawati, R. (2013). Analisis Pengaruh Kualitas Pelayanan Terhadap Loyalitas Pelanggan Jasa Pengiriman Pos Kilat Khusus. Jurnal Teknik Industri, 1(2), 96-107.

Arab, T. M. S. M. G., Rashidian, A., Rahimi, A., Forushani, \& EZarei. (2012). The Effect of Service Quality on Patient loyalty.A Study of Private Hospitals in Tehran, Iran. Iranian J Publ Health, 41(9), 71-77.

Aryani, D., \& Rosita, F. (2010). Pengaruh Kualitas Layanan terhadap Kepuasan Pelanggan dalam Membentuk Loyalitas Pelanggan. Jurnal Ilmu Administrasi Dan Organisasi, 17(2), 114-126.

Ayu, E., \& Edwar, M. (2011). Pengaruh Kualitas Layanan Terhadap Kepuasan Konsumen Pengguna Jasa Travel CV. Panca Indra Abadi Wisata Sidoarjo. EJournal Mahasiswa Universitas Negeri Surabaya, 1-14.

Caceres, C. R., \& Paparoidamis, N. G. (2005). Service quality,relationship satisfaction, trust, commitment and business-to-business loyalty. European Journal of Marketing, 41(7), 836-867.

Chanming, C., \& Jianjun.C. (2011). An Empirical Analysis of the Relationship Among the Service Quality, Customer Satisfaction and Loyalty of High Speed Railway Based on Structural Equation Model. Canadian Social Science, 7(4), 67-73.

Haryono, G., \& Evanita, S. (2015). Pengaruh Dimensi Kualitas Pelayanan Terhadap Loyalitas Pelanggan PT. Jambi Permata Tour Dan Travel Di Sungai Penuh. EJornal Universitas Negeri Padang. 
Henriawan, D. (2015). Pengaruh Kualitas Pelayanan Dan Kepuasan Pelanggan Terhadap Loyalitas Pelanggan (Studi Kasus pada Toko Cabang Mufin Wilayah Bandung Timur). Jurnal Coopetition (Ikopin) Universitas Sebelas April, VI(2), 71-82.

Irnandha. (2016). Pengaruh Kualitas Layan-an terhadap Loyalitas Pelanggan yang Dimediasi oleh Kepuasan Pelanggan Jasa Pengiriman Jalur Darat. Universitas Negeri Yogyakarta.

Karita, P. S., Wardana, M., \& Suasana, K. A. G. (2015). Peran Kepuasan Pelanggan dalam Memediasi Pengaruh Kualitas Produk terhadap Loyalitas Pelanggan pada produk pewangi pakaian Molto di Kota Denpasar. E-Jurnal Manjemen Unud, 4(3), 715-730.

Lee, S. H. (2013). Major Moderators Influencing the Relationships ofService Quality, Customer Satisfaction and Customer Loyalty. Asian Social Science, 9(2).

Merkusi, M. O., \& Devilia, S. D. (2015). Pengaruh Kualitas Pelayanan Terhadap Kepuasan Pelanggan (Studi Pada Tour Dan Travel Di Koper Komunika Indonesia Yogyakarta). E-Proceeding of Management, 2(3), 3525-3533.

Mosahab, R., Mahamad, O., \& Ramayah. (2010). Service Quality, Customer Satisfaction and Loyalty: A Test of Mediation. International Business Research, 3(4).

No Title. (2017).

Oka, Y. A. (2005). Perencanaan Strategis Pemasaran Daerah Tujuan Wisata. Jakarta: Pradnya Paramita.

Prayoga, P. B., W, K. N. M., \& A, S. (2014). Pengaruh Kualitas Pelayanan Terhadap Kepuasan dan Loyalitas Pelanggan Pada Ramayana Department Store di Kota Denpasar. E-Jurnal Manajemen Universitas Udayana, 3(10), 2942-2959.

Pribadi, A. K. (2014). Analisis Pengaruh Kualitas Layanan Terhadap Loyalitas Pelanggan Di PO. Bugar Indah Tour Caruban. Universitas Pembangunan Nasional "Veteran" Jawa Timur.

Raharjo, A. (2013). Pengaruh kualitas produk terhadap loyalitas konsumen yang dimediasi oleh kepuasan konsumen pengguna kartu AS. Jurnal Manajemen, 9(1), 30-44.

Shahin, A., \& Dabestani, R. (2010). Correlation Analysis of Service Quality Gaps in a Four-Star Hotel in Iran. International Business Research, 3(3), 40-46.

Siddiqi, O. K. (2011). Interrelations between Service Quality Attributes,Customer Satisfaction and Customer Loyalty in the Retail BankingSector in Bangladesh. 
I Gede Benny Subawa, Kualitas Pelayanan Berpengaruh...

International Journal of Business and Management, 6(3).

Sinaga, H. P. P. (2010). Analisis Pengaruh Kualitas Pelayanan, Kepuasan Pelanggan, Dan Lokasi Terhadap Loyalitas Pelanggan (Studi Kasus Pada Warnet Chamber Semarang). Universitas Diponegoro.

Singh, D. A. P., \& Thakur, S. (2012). Impact of Service Quality onCostomer Satisfaction and Loyalty: In The Context of Retail Outlets in DB City Shopping Mall Bhopal. Internasional Journal of Management Research and Review, 2(12).

Sumertana, I. W. (2016). Pengaruh Kualitas Pelayanan terhadap Loyalitas Pelanggan dengan Kepuasan Pelanggan sebagai Variabel Intervening pada Water Park Seririt Singaraja tahun 2014-2015. Jurnal Program Studi Pendidikan Ekonomi, 7(2), 1-10. 